\title{
Health advisers (contact tracers) in sexually transmitted disease
}

\author{
R N THIN \\ President, Society of Health Advisers in STD, St Thomas' Hospital, London SE1 7EH
}

SUMMARY Contact tracing has always been a vital element in the control of sexually transmitted disease (STD), and the early full time contact tracers were more effective than doctors in this work. Those appointed to the early posts had to train themselves and they concentrated on contact tracing. Training has now improved, and most contact tracers in Britain, now called Health Advisers in STD, have attended a full time five day residential training course, and it is hoped that better courses may be developed. A handbook has been produced and widely circulated. The Society of Health Advisers in STD holds regular regional meetings and an annual conference. Health advisers may discover personal problems and have an important role in education, both of which activities are covered in their role specification. Health advisers in STD have developed from contact tracers to undertake a broad range of functions, but the question is asked whether they could contribute to other aspects of health care within the clinic.

\section{Introduction}

To control an outbreak of infectious disease the source must be identified and eliminated, and all contacts must be traced and treated. This principle applies to sexually transmitted disease (STD) with the same force as it does to smallpox. Wigfield reviewed the published reports on this subject, and suggested that the earliest organised contact tracing started in Britain in 1937 in north east England. ${ }^{1}$ Although it is clear that many contacts were traced, no comparison was made with the situation before the scheme started. Subsequently, contact slips were widely issued by doctors in clinics but they had limitations. For example, in one report only six source contacts attended from 100 patients. $^{2}$

In the late 1950s in Britain the incidence of gonorrhoea started to rise after the post second world war fall. This rise was thought to be partly due to infected prostitutes and casual partners who were difficult to trace. In 1963 the first health workers with prime responsibility for contact tracing were appointed to clinics at the London Hospital and St Thomas' Hospital, and the tracing of source and secondary contacts improved considerably. ${ }^{3}$ In 1968 new regulations came into force removing certain diffi-

Address for reprints: Dr R N Thin, Department of Genitourinary Medicine, St Thomas' Hospital, London SE1 7EH

Accepted for publication 19 December 1983 culties in communicating confidential information between those engaged in contact tracing. ${ }^{4}$ In 1969 the Report of the Chief Medical Officer to the Department of Health and Social Security endorsed the value of contact tracing. ${ }^{5}$ In 1971 a meeting at the DHSS accepted the value of contact tracers and recommended that every clinic in London should appoint contact tracers who would be on duty during all the hours the clinics were open, to interview all patients with syphilis and gonorrhoea about their contacts. Thereafter the number of clinics with contact tracers increased throughout the country. During their work these health workers gradually learned how many of the patients had social, domestic, personal, and emotional problems. Health workers had the opportunity to listen, discuss, offer simple advice, and refer patients to the clinic doctor, to their general practitioner, or to other agencies as indicated.

Those appointed to these posts came from a wide variety of backgrounds including nursing, health visiting, and social work; others had little or no previous health care training. The main needs were interest, enthusiasm, determination, and a caring attitude. In 1969 they formed a society which has had various names and is now called the Society of Health Advisers in Sexually Transmitted Diseases. The workers are called health advisers in sexually transmitted diseases. The aim of this paper is to describe their training and role in a clinic, and to mention some possible developments in the future. 
TRAINING

The early health advisers largely trained themselves after a little preliminary instruction from medical staff in taking histories. They developed techniques to help patients understand their disease, identify source and secondary contacts, and to motivate patients to trace contacts when possible. Initially health advisers visited a relatively high proportion of contacts, and this required special skills. Lately greater emphasis has been placed on motivating patients to do their own tracing. As more health advisers were appointed newcomers sat in with experienced colleagues, and this is still an important form of training. It is also useful for health advisers to visit several clinics and see how they are managed.

As part of a research programme set up by the Health Education Council (HEC), a Handbook on contact tracing in sexually transmitted diseases was published in 1980.6 This was the first textbook on this subject in the world, and covered medical aspects of the diseases, the running of a clinic, interviewing, record keeping, and legal aspects. The book was issued to all clinics in Britain, and has been requested by centres elsewhere in Britain and abroad.

In 1981, as a result of the enthusiastic activity of council members of the Society of Health Advisers in STD and the then Consultant Adviser in Genitourinary Medicine (Dr R D Catterall) to the Chief Medical Officer, five day residential training courses were started for health advisers. These courses covered clinical and epidemiological aspects of the diseases, sexuality, interviewing and other interpersonal skills, contact tracing, team work, and working with groups. They also provided an opportunity for health advisers to develop a closer sense of identity and trust. Most established health advisers have now attended one of the seven courses held to date, and some experienced health advisers have assisted as members of the tutorial teams. The courses have made an important and welcome contribution to training. It is hoped that until new arrangements are made, these courses will continue to be held as the need arises for newly appointed health advisers.

It is also hoped that in the future more comprehensive training will become available, and investigations are presently under way to see if any established training courses for other health workers could be adapted, or a special module added for health advisers. Representatives of the DHSS and the newly established NHS Training Authority are active in these discussions.

The Society of Health Advisers in STD hold a two day annual meeting at which guests and members present papers. This meeting is an important part of continuing training, a forum for discussing problems, an opportunity for sharing experiences and ideas, and a chance for health advisers to meet.

\section{CURRENT ROLE OF HEALTH ADVISERS- \\ ROLE SPECIFICATION}

The present role specification for health advisers in STD has been informally accepted by the DHSS.

\section{Guidelines for appointing health advisers}

The role specification includes guidelines for appointing health advisers. Among these are the need to provide adequate facilities such as a room for interviewing in privacy, a direct external telephone, a car, car user's allowance, or mileage payments to facilitate visiting, and clerial assistance if needed. Provision for sickness and holiday relief must be considered essential to provide a service throughout the year. Newcomers to health advising should have a suitable personality, be at least 25 years old, and have had three years' training in some related discipline such as nursing or social studies. Before starting work, newcomers should have some preliminary training with an experienced health adviser and should have some theoretical instruction in STD (such as attendance at a course of student lectures). It is mandatory that they attend the next available five day training course. Arrangements should be made for a senior health adviser from the Society of Health Advisers in STD to keep in touch with every newcomer to help with training and problems, and the assessment of suitability after the probationary period of the appointment. In service training, including attendance at meetings for health advisers, should be organised.

\section{Contact tracing}

The essential function of the health adviser is to interview each patient with syphilis, gonorrhoea, or other STD to identify sexual contacts at risk and obtain their attendance at a clinic. Consultants delegate responsibility for contact tracing and related functions to health advisers, who are directly responsible to the consultants for all aspects of their work. The health adviser works in cooperation with all other clinic staff and is accountable to the administration only for personnel matters.

\section{Record keeping}

One project on the HEC research programme was to devise a record system. This took the form of cards, which simplify keeping an accurate record of contact action, allow collection of statistics, and facilitate exchange of information between clinics. ${ }^{7}$

\section{Education}

Education of individual patients about their disease helps cooperation with treatment, contact tracing, 
and surveillance. Health advisers also have an important role in educating many other groups of health workers in hospitals and elsewhere and members of the public.

\section{Guidance}

Social, emotional, and personal problems should also be considered. Simple problems can be discussed and more complex problems referred; a list of local agencies which manage such problems should be maintained.

\section{Other activities}

Other activities include exchanging relevant details with colleagues in other clinics, tracing defaulters from surveillance, and continuing education to ensure high standards of practice.

\section{Discussion}

Health advising has developed widely in Britain, although a few clinics still lack full time cover. While contact tracers are well established in the USA ${ }^{8}$ and have been appointed in other countries, in many countries their number is inadequate; Australia provides an example of this problem. ${ }^{9}$ The increased number of health advisers in Britain my be a factor in the decline in incidence of gonorrhoea in recent years. ${ }^{10}$ The appearance of $\beta$-lactamase producing gonococci has increased the need for rapid effective contact tracing. After the initial presumed importation, the spread in Liverpool was contained by contact action, ${ }^{11}$ but these organisms now appear to be established in Britain. ${ }^{12} 13$

The introduction of the need for preliminary academic training and an age limit for entry ensures intellectual ability and maturity. Health advisers currently come from various backgrounds and this is to be encouraged. Progress has been made with training but, as in many new professions, much remains to be done. The educational activities of health advisers need emphasis. Health advisers educate patients on an individual basis. Many health advisers undertake some education in and around their clinic and hospital. There is still, however, widespread ignorance about STD, genitourinary medicine, and the work of health advisers. Groups that need educating include clinic medical and other staff, hospital medical and other staff, general practitioners and their staff, family planning clinic staff, school medical officers, health educators of all sorts, and pupils and teachers in schools, colleges, and elsewhere. This list is not intended to be comprehensive, but does illustrate the scale of the problem and prompts the question: Do all clinic doctors make the best use of their health adviser's educational ability?
Some health advisers may have more skills in counselling and guidance, others may prefer education. Clinics with more than one post may find it helpful to appoint individuals with complementary skills in different fields.

Perhaps one of the greatest gaps in our present knowledge is information on the present value of contact tracing since all the recent developments. In one survey seven years ago a newly appointed health adviser noted that during the six months before her appointment patients with gonorrhoea had named 56 contacts, of whom 18 attended a clinic in Britain. During the next six months a similar number of patients named 181 contacts, of whom 73 attended a clinic in Britain and 24 of the remainder were known to be abroad. ${ }^{14}$ Such data pose questions about the efficacy of contact tracing in clinics that lack full time cover from dedicated health advisers, however enthusiastic the doctors and other staff may be. Health advisers have also contributed to recent studies on the infectivity of syphilis, gonorrhoea, and candidosis. ${ }^{15} 16$

Medical staff might consider with health advisers other contributions to health care of patients. Many health advisers act as referral agencies for advice on social problems, psychosexual problems, contraception, and pregnancy. Some clinics think they have a responsibility for follow up of patients with dysplastic cervical cytological smears, and many recommend that homosexuals should have regular examinations. Have health advisers a role in these and other aspects of health care?

Health advisers have developed from traditional contact tracers to undertake a broad range of functions working with other members of the clinic team. They are intelligent, enthusiastic people whose training, although better than before, can certainly be improved to increase their value to their clinic and to health care.

I thank Peter Lewis, Maureen Martin, Dr C B S Schofield, and Patricia White for their help in preparing this paper.

\section{References}

1. Wigfield AS. 27 years of uninterrupted contact tracing. The Tyneside Scheme, Br J Vener Dis 1972; 48:37-50.

2. Dunlop EMC, Lamb AM, King DM. Improved tracing of contacts of heterosexual men with gonorrhoea. Br J Vener Dis 1971;47:192-5.

3. Muspratt B, Ponting LT. Improved methods of contact tracing. Br J Vener Dis 1967; 43:204-9.

4. Department of Health and Social Security. National Health Service (Venereal Diseases) Regulations 1968. London: HMSO (Statutory Instrument No 1624).

5. Department of Health and Social Security. Annual Report of the Chief Medical Officer of Health for 1969. London: HMSO; 65. 
6. Hunter I, Jacobs J, Kinell H. Satin A. Handbook on contact tracing in sexually transmitted disease. London: The Health Education Council, 1980.

7. Satin A. A record system for contact tracing. Br J Vener Dis 1977;53:84-7.

8. Roberts RB. Prevention and control of the sexually transmitted diseases. In: Catterall RD, Nicol CS, eds. Sexually transmitted diseases. London: Academic Press, 1976;51-61.

9. Bradford DL, Philpot CR. A survey of sexually transmitted disease centres in Australia. Br J Vener Dis 1983;59:330-4.

10. Communicable Disease Centre. Sexually transmitted disease surveillance 1981. Br Med J 1983; 286:1500-1.

11. Arya OP, Rees E, Percival A, Alergant CD, Annels EH, Turner GC. Epidemiology and treatment of gonorrhoea caused by penicillinase producing strains in Liverpool. Br J Vener Dis 1978; 54:28-35.
12. McCutchan JA, Adler MW, Berrie JRH. Penicillinase producing $N$ gonorrhoeae and development of endemic transmission. Br Med J 1982; 285: 337-40.

13. Thin RN, Barlow D, Eykyn S, Phillips I. Imported penicillinase producing Neisseria gonorrhoeae become endemic in London. Br J Vener Dis 1983;59:364-8.

14. Rendell P. The work of a contact tracer. St Bartholomew's Hospital Journal. 1977;36-9.

15. Thin RN, Rendell P, Wadsworth J. How often are gonorrhoea and genital yeast infection sexually transmitted? BrJ Vener Dis 1979;55: 278-80.

16. Schober PC, Gabriel G. White P, Felton WF, Thin RN. How infectious is syphilis? Br J Vener Dis 1983;59:217-9. 